\title{
Long term components in polar motion $\left(^{*}\right)$
}

\author{
E. Proverioto - V. Quesada (**)
}

Received on January 12, 1972

SUMmary. - The analysis of a long series of latitude observations carried out in the International Latitude Station has allowed a very careful study of forced motion due to meteorological effects and of the remaining motion ascribed to the free nutation of an elastic Earth. The discussion of these observations has, however, led to the discovery of the existence of long term components in polar motion $\left({ }^{6.8}\right)$. These results have recently been confirmed by Proverbio et al. $\left({ }^{11}\right)$.

In this work, the latitudes observed in the period 1900.0 - 1969.0 reducod to a single homogeneous system are analyzed separately for the five stations of the ILS. The analysis of this quantity points up the existence of two different long term components in polar motion of about 16 and 26 years. One possible interpretation of these phenomena is based on "beat " phenomena between the nutation of the mantle and the inner core of the Earth $\left({ }^{2}\right)$.

Riassunto. - L'analisi della lunga serie di osservazioni di latitudine effettuata nelle stazioni internazionali ha permesso uno studio molto accurato delle componenti annuali dovute a cause meteorologiche ed a quella chandleriana del moto polare.

La discussione di queste osservazioni ha tuttavia rilevato l'esistenza di componenti a lungo termine nel moto del polo $(6,8)$. Questi risultati sono stati confermati recentemente da Proverbio et al. (11).

In questo lavoro sono analizzate, separatamente per le cinque stazioni del SIL, le latitudini osservate nel periodo 1900.0-1969.0 ridotte ad un unico sistema omogeneo. L'analisi di questa quantiti motte in evidenza l'esistenza di due differenti termini a lungo periodo nel moto del polo di circa 16 e 26 anni. Una possibile interpretazione di questi fenomeni e basata su fenomeni di battimento fra la nutazione del mantello o del nucleo interno della Terra $\left({ }^{2}\right)$.

(*) Lavoro presentato al Congresso annuale della S.I.F. (Sezione Fisica cosmica ed Astrofisica), L'Aquila, 1971.

$\left.{ }^{* *}\right)$ Stazione Astronomica Internazionale di Latitudine, Cagliari-Carloforte. 


\section{1. - INTRODUCTION}

1.1 - Analysis of the latitude observations made in the International Latitude Service Stations starting from 1899 has supplied important knowledge on polar motion and on the causes of this motion, particularly on the causes of the Chandler component owing to the free nutation of the elastic Earth. Nlthough the true nature of this motion still constitutes a problem of difficult solution, at least three models have been proposed as an explanation of the Chandler wobble:

a) the so-called linear damped model introduced by Jefirreys (1940) and developed by Walker and Young (1955);

b) the time variable model proposed by Melchior (9, 10) based on a resonance phenomenon of the variable frequency of the free nutation;

$c$ ) the two frequency model proposed in order to explain the bifurcation of the Chandler wobble recently confirmed also by the power spectrum analysis of Gaposchkin (5).

According to Colombo and Shapiro $\left({ }^{4}\right)$ this phenomenon can be explained by viscous coupling between two layers in the upper mantle that would give rise to two distinct frequencies in the Chandler motion.

The possibility prospected by the two frequency model of a hypothetical coupling between the two different layers of the mantle or core as a basis of beat phenomena opens up notable prospects for explaining not only the mechanism of the Chandler wobble, but also to explain the existence of long term polar motion variations recently reported on.

1.2 - The existence of long term polar motion variations reported by Hattori $\left(^{6}\right)$ was pointed up by Markowitz $\left({ }^{8}\right)$. From the analysis of polar motion Markowitz finds the existence of an empirical libration of the Earth's axis with a 24 year period in the direction $132^{\circ} \mathrm{W}$ or $48^{\circ} \mathrm{E}$. More recently, Proverbio et al. (11) in analysing the amplitude spectrum as a function of the periods, confirmed the existence of this long term polar motion component, which can be represented by the equations

$$
\begin{aligned}
& x=0^{\prime \prime} .023 \sin \left(\frac{2 \pi t}{26}+170\right) \\
& y=0^{\prime \prime} .024 \cos \left(\frac{2 \pi t}{24}+210\right)
\end{aligned}
$$




\section{2. - I}

2.1 - The analysis carried out by Proverbio et al. (11) utilizing the values of the polar coordinates $x$ and $y$ for the period 1900.0-1961.9, calculated starting from the homogeneous latitude system $\Phi_{\text {II }}\left({ }^{13}\right)$ led to the singling out of two distinct periods of about 26 and 24 years in the coordinates $x$ and $y$ respectively, as can be seen from equation [1]. However, with this analysis, as with that of Markowitz, polar variations are not deduced directly starting from the latitudes observed, but indirectly by using, as has been said, the values of the polar coordinates $x$ and $y$. In the case of long term variations of a non-polar nature in the latiturle of one or more stations, this could somehow alter the results of the analysis itself.

In this work, the analysis was extended to the latitudes observed in the five stations of the IISS in the period 1900.0 - 1969.0. For this reason, the latitude values in the $\Phi_{\text {II }}$ system published by Proverbio et al. $\left({ }^{13}\right)$ for the period $1900.0-1962.0$ were used, while for the interval from 1962.0 to 1969.0 the values of the latitudes observed published in the Annual Report of the International Polar Motion Service from 1962 to 1969 were averaged, reduced to the system $\Phi_{\text {II }}$ and interpolated for every tenth of a year $\left(^{3}\right)$ by means of the equation

$$
\Phi_{\mathrm{II}}^{(i)}=\Phi_{\mathrm{obs}}^{(i)}-Z \quad(i=1,2, \ldots, 5)
$$

where $Z$ represents the international $Z$ term calculated by the IISS.

In Table I the original values of the latitude $\Phi_{\mathrm{iI}}^{i}$ for the five stations of the IISS for the period $1962.0-1969.0$ are given. From these values, using the F60 filter ( $s_{50 / 2} / 60$ in the notation of Labrouste) the filtered latitudes by tenths of a year were obtained. These are given in Table II. On the other hand, the latitude values given in Table III represent the anmual means of the filtered latitudes and, together with those calculated and published previously by Proverbio et al. $\left({ }^{12}\right)$ for the period 1903.5 - 1958.5 , represent the observational material used here.

2.2 - Spectrum in amplitude of the frequency with the period $T$ included between $T$ and 40 years had been calculated by the least squares method utilizing the observational equation in the form

$$
\Lambda \Phi_{i}^{(i)}=\Phi_{t}^{(i)}-\Phi_{o}^{(i)}=a^{(i)}+b^{(i)} t+A^{(i)} \sin \left[\frac{2 \pi t}{T}+B^{(i)}\right\rceil \quad(i=1,2, \ldots 5)
$$


'Table I

\begin{tabular}{|c|c|c|c|c|c|c|c|c|c|c|c|}
\hline & $M: 2$ & UKI & CAR & GAI & $K I T$ & & $M I Z$ & UKI & CAR & GA! & KIT \\
\hline $\begin{array}{l}1932.0 \\
1962.1 \\
1962.2 \\
1962.3 \\
1962.4 \\
1962.5 \\
1962.6 \\
1952.7 \\
1952.8 \\
1952.9 \\
1963.5 \\
1963.1 \\
1963.2 \\
1963.3 \\
1963.4 \\
1963.5 \\
1963.6 \\
1963.7 \\
1953.8 \\
1963.9 \\
1964.0 \\
1964.1 \\
1964.2 \\
1954.3 \\
1964.4 \\
1964.5 \\
1964.6 \\
1964.7 \\
1964.8 \\
1964.9 \\
1965.0 \\
1965.1 \\
1965.2 \\
1965.3 \\
1965.4\end{array}$ & $\begin{array}{l}3.386 \\
3.368 \\
3.312 \\
3.286 \\
3.320 \\
3.358 \\
3.462 \\
3.500 \\
3.530 \\
3.524 \\
3.477 \\
3.434 \\
3.316 \\
3.208 \\
3.174 \\
3.220 \\
3.310 \\
3.504 \\
3.586 \\
3.584 \\
3.590 \\
3.480 \\
3.350 \\
3.210 \\
3.120 \\
3.119 \\
3.220 \\
3.296 \\
3.406 \\
3.523 \\
3.576 \\
3.562 \\
3.492 \\
3.402 \\
3.264\end{array}$ & $\begin{array}{l}12.376 \\
12.356 \\
12.334 \\
12.284 \\
12.204 \\
12.133 \\
12.140 \\
12.236 \\
12.298 \\
12.379 \\
12.468 \\
12.478 \\
12.444 \\
12.349 \\
12.273 \\
12.140 \\
12.067 \\
12.076 \\
12.166 \\
12.266 \\
12.350 \\
12.502 \\
12.596 \\
12.571 \\
12.410 \\
12.270 \\
12.154 \\
12.075 \\
12.100 \\
12.149 \\
12.268 \\
12.380 \\
12.528 \\
12.575 \\
12.553\end{array}$ & $\begin{array}{l}8.924 \\
8.928 \\
81984 \\
9.053 \\
9.074 \\
9.048 \\
9.034 \\
91952 \\
8.862 \\
8.800 \\
81792 \\
8.830 \\
8.902 \\
9.018 \\
91120 \\
9.166 \\
9.164 \\
9.070 \\
8.940 \\
8.772 \\
8.710 \\
8.698 \\
8.746 \\
8.764 \\
8.990 \\
9.082 \\
9.146 \\
9.148 \\
9.036 \\
8.940 \\
8.826 \\
8.740 \\
8.676 \\
8.662 \\
8.750\end{array}$ & $\begin{array}{l}13.450 \\
13.479 \\
13.476 \\
13.389 \\
13.346 \\
13.288 \\
13.240 \\
13.246 \\
13.294 \\
13.396 \\
13.459 \\
13.507 \\
13.545 \\
13.550 \\
13.500 \\
13.440 \\
13.294 \\
13.220 \\
13.172 \\
13.240 \\
13.318 \\
13.421 \\
13.527 \\
13.615 \\
13.591 \\
13.530 \\
13.465 \\
13.346 \\
13.295 \\
13.260 \\
13.260 \\
13.266 \\
13.385 \\
13.487 \\
13.545\end{array}$ & $\begin{array}{l}1.524 \\
1.580 \\
1.696 \\
1.701 \\
1.776 \\
1.878 \\
1.854 \\
1.812 \\
1.760 \\
1.654 \\
1.562 \\
1.516 \\
1.521 \\
1.589 \\
1.718 \\
1.824 \\
1.850 \\
1.920 \\
1.840 \\
1.730 \\
1.620 \\
1.554 \\
1.507 \\
1.503 \\
1.578 \\
1.596 \\
1.784 \\
1.860 \\
1.921 \\
1.910 \\
1.820 \\
1.674 \\
1.592 \\
1.530 \\
1.492\end{array}$ & $\begin{array}{l}1965.5 \\
1965.6 \\
1965.7 \\
1965.8 \\
1965.1 \\
1966.0 \\
1966.1 \\
1966.2 \\
1966.3 \\
1966.4 \\
1966.5 \\
1966.6 \\
1966.7 \\
1966.1 \\
1966.9 \\
1967.0 \\
1967.1 \\
1967.2 \\
1967.3 \\
1967.4 \\
1967.5 \\
1967.6 \\
1967.7 \\
1967.8 \\
1967.9 \\
1968.0 \\
1968.1 \\
1968.2 \\
1968.3 \\
1968.4 \\
1968.5 \\
1968.6 \\
1968.7 \\
1968.8 \\
1968.9\end{array}$ & $\begin{array}{l}3.210 \\
3.206 \\
3.244 \\
3.273 \\
3.376 \\
3.418 \\
3.500 \\
3.530 \\
3.494 \\
3.329 \\
3.320 \\
3.370 \\
3.308 \\
3.288 \\
3.310 \\
3.360 \\
3.456 \\
3.460 \\
3.454 \\
3.398 \\
3.382 \\
3.394 \\
3.402 \\
3.420 \\
3.418 \\
3.390 \\
3.330 \\
3.300 \\
3.296 \\
3.324 \\
3.320 \\
3.400 \\
3.420 \\
3.460 \\
3.496\end{array}$ & $\begin{array}{l}12.513 \\
12.344 \\
12.243 \\
12.180 \\
12.244 \\
12.278 \\
12.275 \\
12.320 \\
12.390 \\
12.408 \\
12.498 \\
12.467 \\
12.358 \\
12.314 \\
12.269 \\
12.285 \\
12.280 \\
12.294 \\
12.324 \\
12.314 \\
12.334 \\
12.356 \\
12.398 \\
12.430 \\
12.500 \\
12.517 \\
12.473 \\
12.476 \\
12.421 \\
12.373 \\
12.311 \\
12.325 \\
12.375 \\
12.464 \\
12.518\end{array}$ & $\begin{array}{l}8.906 \\
9.034 \\
9.118 \\
9.130 \\
9.006 \\
9.962 \\
8.916 \\
8.796 \\
8.764 \\
8.759 \\
8.780 \\
8.876 \\
9.012 \\
9.020 \\
8.975 \\
8.984 \\
9.962 \\
8.942 \\
8.932 \\
8.912 \\
8.984 \\
8.962 \\
8.912 \\
8.776 \\
8.869 \\
8.926 \\
8.957 \\
8.988 \\
8.968 \\
8.960 \\
9.016 \\
9.022 \\
8.940 \\
8.854 \\
8.826\end{array}$ & $\begin{array}{l}13.575 \\
13.561 \\
13.416 \\
13.372 \\
13.289 \\
13.270 \\
13.264 \\
13.277 \\
13.324 \\
13.367 \\
13.442 \\
13.492 \\
13.492 \\
13.460 \\
13.452 \\
13.390 \\
13.292 \\
13.274 \\
13.269 \\
13.252 \\
13.286 \\
13.310 \\
13.300 \\
13.317 \\
13.390 \\
13.393 \\
13.341 \\
13.333 \\
13.326 \\
13.285 \\
13.281 \\
13.263 \\
13.230 \\
13.238 \\
13.295\end{array}$ & $\begin{array}{l}1.558 \\
1.673 \\
1.718 \\
1.768 \\
1.852 \\
1.861 \\
1.808 \\
1.770 \\
1.680 \\
1.610 \\
11592 \\
1.590 \\
1.594 \\
11646 \\
1.696 \\
1.714 \\
1.724 \\
1.705 \\
1.724 \\
1.750 \\
1.742 \\
1.698 \\
11686 \\
1.650 \\
1.5585 \\
1.575 \\
111585 \\
110676 \\
1.724 \\
1.719 \\
11726 \\
1.779 \\
1.748 \\
1.646 \\
1.576\end{array}$ \\
\hline
\end{tabular}

where $t=\tau_{n}$ represents a generic epoch included in an interval $N$. By means of this procerlure in the calculated spectrum of the amplitudes the spectral line corresponding to the apparent periods $T^{\prime}=T+\Delta T$ is represented by broadened main peaks accompanied by a series of other yearly peaks $\left({ }^{7}\right)$. The band width of the main peaks can be deduced from the quality factor $Q$ corresponding to each peak and calculated by means of the expression

$$
1 / Q_{T^{\prime}}=8.85 \frac{T^{\prime \prime} \tau^{\prime}}{N^{\prime} \tau} \cdot 10^{-2}
$$

where $\tau, \tau^{\prime}$ represent the units with which the intervals $t$ (or $T$ ) and $N$ are expressed.

Since the apparent period $T^{\prime}$ can be held to be very close to the real period $T$ for $N \gg 1$, this procerlure can be considererl to be, as a first approximation, sufficiently capable of pointing up the existence of long term polar motion components with periods on the order of those already singled out.

Since the interval $N$ considered here results as 62 years $(\tau=1)$ putting into [2] successively $T_{16}^{\prime}=16$ years and $T^{\prime 26}=26$ years 


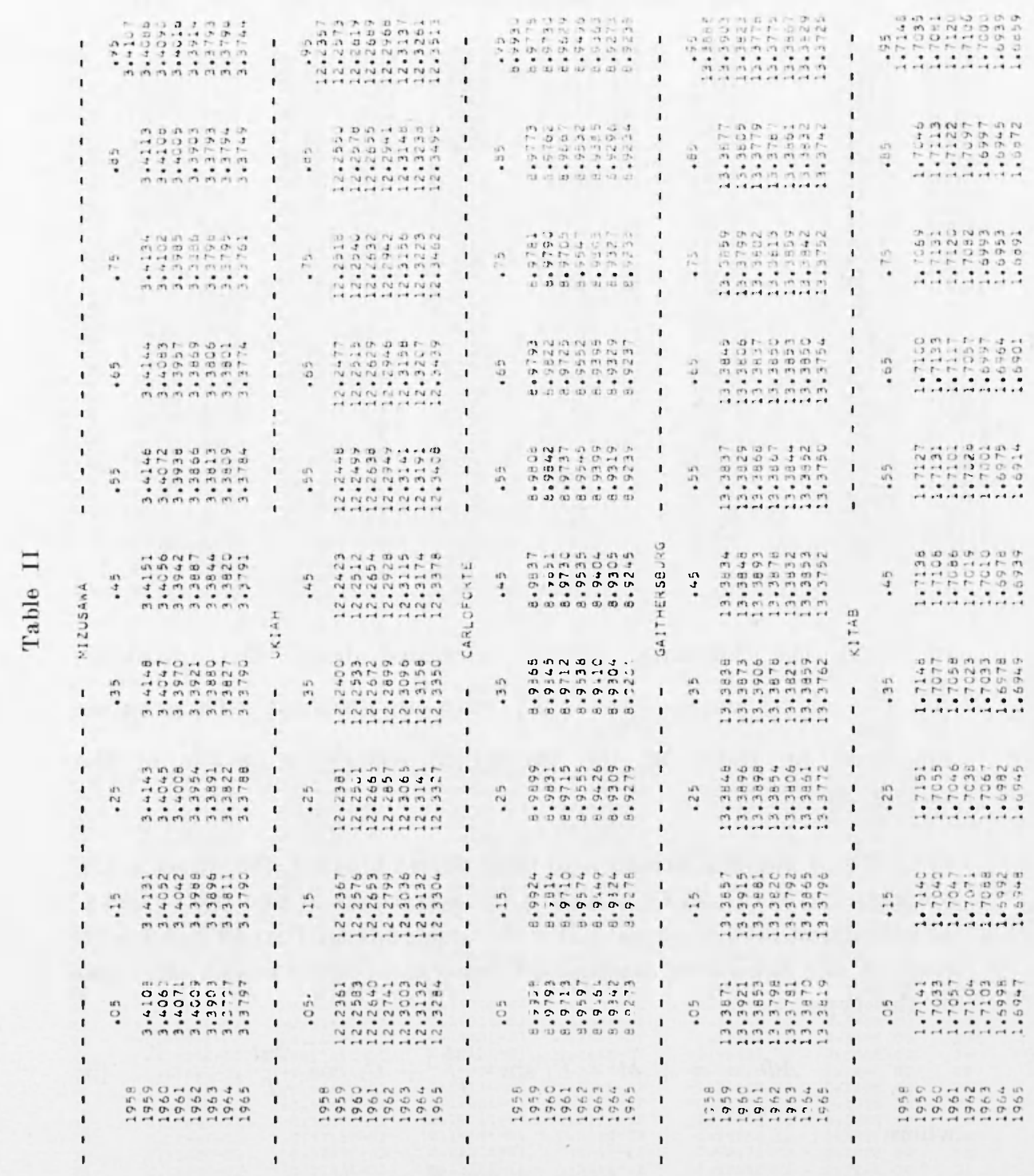


Table III

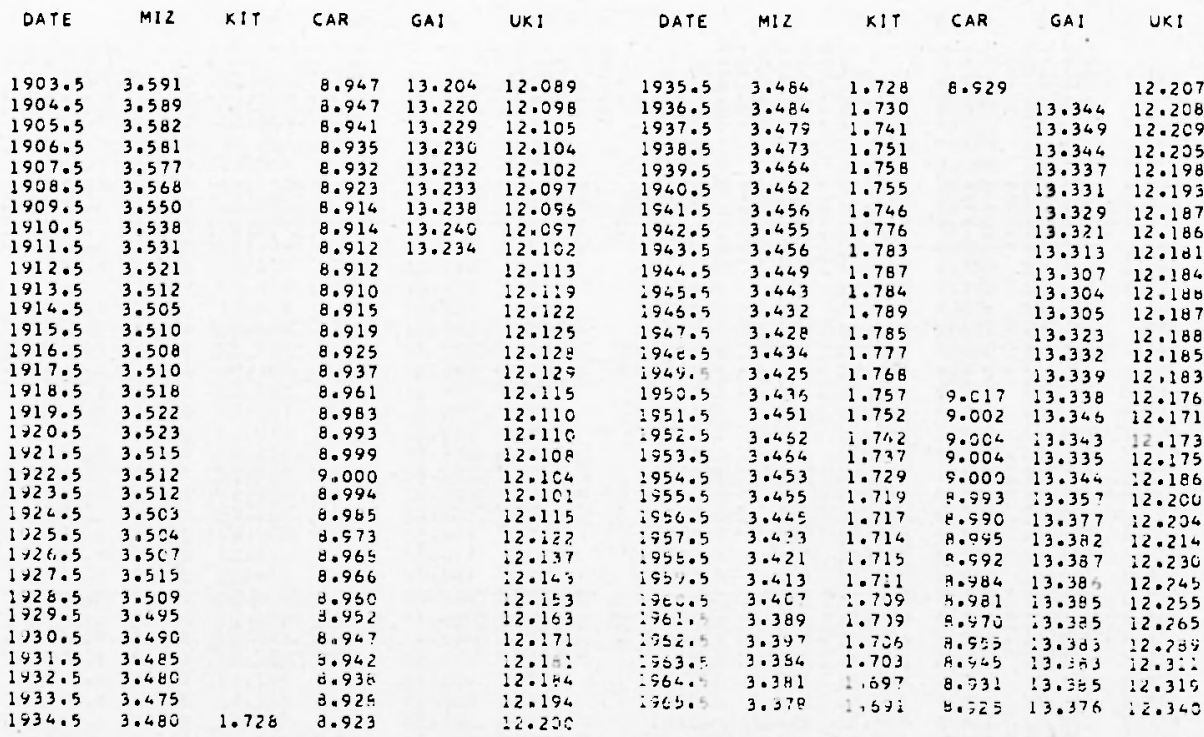

$\left(\tau^{\prime}==1\right)$ the following values calculated from the quantities $\frac{1}{\gamma}: \frac{1}{\gamma_{16}}=2.3$ years, $\frac{1}{Q_{26}}=3.7$ years are obtained. These values constitute an index of the theoretical separating power of the method used here.

2.3 - Using the latitude values given in Table III, the values of the quantities $a, b, C_{1}$ and $C_{2}$ as well as the amplitudes $A$ and the phases $F$ as a function of the period $T$, for $T$ variable from $i$ to 40 years with steps of one year were calculated by means of equations of condition of the type

$$
\Delta \Phi=a+b t+C_{1} \sin \frac{2 \pi t}{\pi}+C_{2} \cos \frac{2 \pi t}{\pi}
$$

where

$$
\begin{aligned}
& C_{1}=A \cos F \\
& C_{2}=A \sin F
\end{aligned}
$$

The calculated values of $C_{1}, C_{2}, A$ and $F$ with the respective m.s.e. are given in Table IV. The values of the amplitudes are represented in 
Table IV

MIZUSAWA

$\begin{array}{lc}7 & C 1 \\ 7 & -0.7153 E-23 \\ 8 & -0.2218 E-C 3 \\ 9 & -0.1051 E-02 \\ 10 & -0.2154 E--2 \\ 11 & -0.2468 E-C 2 \\ 12 & -0.1263 E-C 2 \\ 13 & 0.5488 E-02 \\ 14 & -0.3163 E-02 \\ 15 & -0.2180 E-02 \\ 15 & 0.1238 E-01 \\ 17 & 0.1443 E-01 \\ 13 & 0.8631 E-02 \\ 29 & C .1380 E-02 \\ 20 & -0.2411 E-03 \\ 21 & 0.3936 E-02 \\ 22 & 0.945 C E-02 \\ 23 & 0.1306 E-01 \\ 24 & 0.1390 E-01 \\ 25 & 0.1221 E-01 \\ 26 & 0.8723 E-02 \\ 27 & 0.4419 E-02 \\ 28 & 0.2836 E-03 \\ 29 & -0.2909 E-02 \\ 30 & -0.4770 E-02 \\ 31 & -C .5327 E-02 \\ 32 & -0.4897 E-02 \\ 33 & -0.3888 E-02 \\ 34 & -0.2651 E-02 \\ 35 & -0.1421 E-02 \\ 36 & -0.3247 E-03 \\ 37 & 0.5836 E-03 \\ 38 & 0.1266 E-02 \\ 39 & 0.1784 E-02 \\ 40 & 0.2065 E-02 \\ & \end{array}$

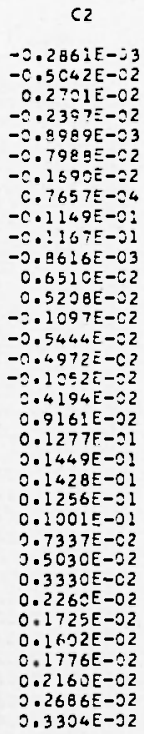

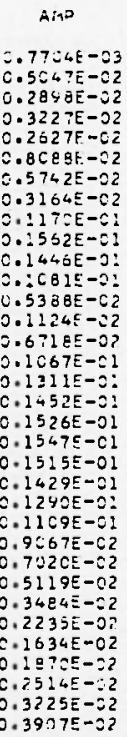

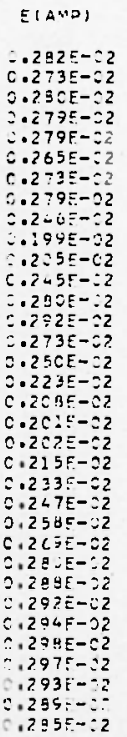

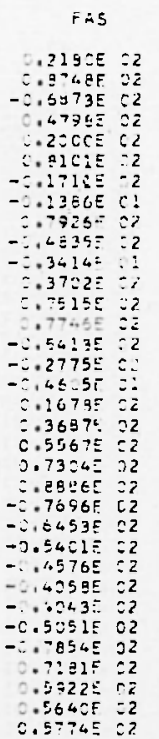

E(F⿻s;

$\therefore: 01200$

O. $159 \mathrm{ES}$ oO

$0.162 \mathrm{~F}$ CS

$0 . \vdots 60 \mathrm{E} \mathrm{CO}$

$2.151 E=0$
.1495

D.56: 22

C.:26. CS

$\because 35 \bar{E} \mathrm{ZJ}$

. 11.1250

2.1225

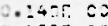

C.:J5e 20

$\therefore 595=$

ว.:55E =

$\because 1445=0$

‥1335 =

$0 .: 15=20$

$2 .: 15=0$.

C.IITE CO

Q. $1235=5$

2.14ङE CO

C.IJ5E GO

¿. ISLE OS

2.164502

Z.157E CE

$0.155 E$ :

$0.1665 \mathrm{CO}$

$0.165 E 00$

C. ¿góe CO

2. 1ESE C?

$.165 E$ CS

\section{GA: THER SBURG}

C1

$0.2291 E-02$

$0.4331 E-0.4$

$0.3295 \mathrm{E}-02$

$-0.9582 E-02$

$0.2206 \mathrm{E}-02$

$0.4585 E-02$

$-0.4489 E-02$

$-0.5429 E-02$

$-0.4009 E-02$

$0.5032 \mathrm{E}-02$

$0.1262 E-01$

$0.1019 E-01$

$0.1262 E-01$
$-0.8667 E-03$

$-0.8667 E-03$

$-0.1965 E-01$

$-0.1704 \mathrm{E}-01$

$-0.8379 E-=2$

$0.1329 E-C 2$

$0.0864 E-C 2$

$0.1326 E-C 1$

$0.1493 \mathrm{E}-01$

$0.1464 \mathrm{~F}-\mathrm{Cl}$

$0.1296 \mathrm{E}-\mathrm{Cl}$

$0.1022 E-01$

$0.6683 \mathrm{E}-02$

$0.2572 \mathrm{E}-\mathrm{C2}$

$-0.178 \mathrm{gE}-\mathrm{CL}_{2}$

$-0.6053 \mathrm{E}-\mathrm{C2}$

$-0.9033 E-C 2$

$-C .1324 \mathrm{E}-\mathrm{C} 2$

$-0.1591 \mathrm{E}-\mathrm{Cl}$

-C.179CE-Cl

$-0.921 F-01$
$-0.1986 E-21$
62

$0.2776 E-02$

C. $2096 \mathrm{E}-02$

$-0.4638 \mathrm{E}-02$

$0.5946 \mathrm{E}-02$

$-0.1025 E-01$

$c .6816 E-02$

$0.3241 E-02$

$-0.1030 E-02$

$-0.9102 E-C 2$

$-0.1170 E-01$

C. $4558 \mathrm{E}-02$

0.7 I $C E-02$

$0.1485 E-01$

$0.1256 E-01$
$C .2490 E-02$

$-0.9080 E-02$

$-0.1619 E-21$

$-2.1741 E-21$

$-0.1430 \mathrm{C}-0$

$-0.9157 E-02$

$-0.35+2 E-C$

$0.1407 E-02$

$0.5755 \mathrm{E}-22$

$3.926 \mathrm{QF}-02$

$3.1183 \mathrm{E}-\mathrm{1}$

$2.13745=2$

C. $1305 E-2:$

$0.1267 E-01$

$0.5: 25 \mathrm{E}-32$

$0.6399 \mathrm{E}=2$

$0.3272 \mathrm{~F}-32$

$-0.6144 F-0.4$
$-\therefore .3478 E-52$
A YP

$0.3599 E-22$

$0.2097 E-02$

$0.569 \mathrm{CE}-\mathrm{C2}$

$0.1127 E-C I$

$0.1049 \mathrm{E}-01$

$0.8215 \mathrm{E}-02$

$0.5537 E-02$

$0.5526 E-02$

$0.9 C 40 E-02$

$0.1273 \mathrm{E}-01$

$0.1342 E-01$

$0.1284 E-01$

$0.1488 \mathrm{E}-\mathrm{Cl}$

$0.1 B 17 E-C 1$

$0.1981 E-C 1$

$0.1931 E-01$

$0.1823 E-01$

$0.1746 \mathrm{E}-01$

$0.1683 E-01$

$0.1612 E-01$

$0.1538 E-01$

$0.1471 E-0$

$0.1418 E-01$

$0.1359 E-C 1$

$0.1359 E-01$

$0.1385 E-\approx 1$

$0.1439 E-21$

$0.1517 E-E 1$

$0.1612 E-51$

$0.1715=-6$

$0.1920 E-21$

$0.1921 E-2$

$6.2 \div 26 E-21$
E (ANP)

FAS

$.377 E-02$ $0.375 E-02$ $0.368 \mathrm{E}-02$ $0.332 \mathrm{E}-02$ $0.343 \mathrm{E}-02$ $0.363 \mathrm{E}-02$ $0.371 E-02$ $0.362 \mathrm{E}-02$ $0.383 E-02$ $0.359 E-02$ $0.330 E-02$ $0.335 \mathrm{E}-02$ $0.294 E-02$ $0.269 \mathrm{E}-02$ $0.255 E-02$ $0.253 \mathrm{E}-02$ $0.263 E-02$ $0.268 \mathrm{E}-02$ $0.276 E-02$ $0.294 \mathrm{E}-02$ $0.303 E-02$ $0.312 E-02$ $0.336 E-02$ $0.356 \mathrm{E}-02$ c. $354 \mathrm{E}-02$ C. $345 E-C 2$ $0.357 E-02$ $0.366 \mathrm{E}-02$ $0.4065-02$ $\therefore .41 \equiv 5-22$ $3.4175-02$ $0.424 E-02$ $0.431 E-62$ $2.434 \mathrm{E}-22$
$0.5047 E \quad 02$ $0.8881 E \quad 02$ $-0.5460 E$ O2 $-0.3182 E_{02}$ $-0.7785 E$ O2 Q.5607E 02 $-C .3582 \mathrm{E} 02$ C.1074E O2 $0.6366 E$ O2 $-0.6672 E$ O2

-0.1985E O2 C.3745E O2 $-0.8666 E$ O2 $-0.4373 E$ O2 $-0.7219 E$ Ol

$0.2804 E 02$ $0.6263 E \mathrm{C2}$ $-0.8563 E 02$ $-2.5821 E 02$ $-0.3465 \mathrm{E} 02$ $-0.1377 \mathrm{E} \mathrm{O2}$ $0.5489 E$ OI C. $2394 \mathrm{E} 02$ C.421?E C2 $\therefore .6055 E 02$ 0.79095 O2 $-0.8258 E \quad 02$ $-C .6513 E 02$ -0.4910 E O2 $-0.3473 E \quad 02$ $-0.2190 E$ O2 - -.1C35E O2 $0.1931 E 00$ $0.9933 \mathrm{E} \mathrm{Cl}$
E(FAS) T

$0.216 E 00$ $0.219 E 00$ $0.211 E 00$ $0.187 E 00$ 0.193 E 00 $0.205 E 00$ $0.216 E 00$ $0.221 E$ OO $0.203 E 00$ $0.196 E$ OO $0.2 C 1 E 00$ $0.187 E 00$ 0.179E OO C.154E OO 0.138 E 00 $0.142 E 00$ $0.149 E 00$ $0.158 E 00$ 0.164 E 00 $0.165 \mathrm{E} 00$ $0.175 E \quad 00$ $0.126 E 00$ $0.192 E 00$ $0.2 \mathrm{C2E} 00$ $0.224 E 00$ $0.245 E ~ O C$ $0.252 E$ C 2 $0.244 E$ OO $0.236 E$ DO $0.231 E 00$ $0.227 E \quad 00$ $0.220 E$ OO $0.213 E 00$ $0.211 E 00$ 
continuation Table IV

UK:AH

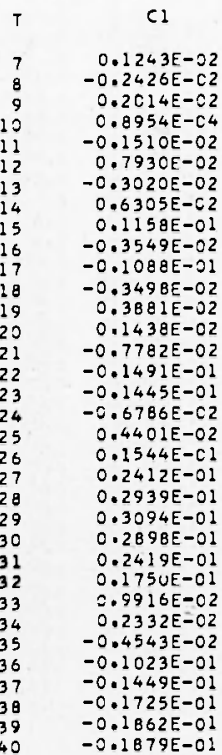

C2

$0.25245=: 2$

$0.3631 \mathrm{E}-.22$

$0.3866 E-02$

$-0.6499 \mathrm{E}-\mathrm{C2}$

$-c .45165-02$

$-0.3364 \mathrm{E}-03$

$0.1056 \mathrm{E}-\mathrm{CE}^{3}$

$-0.7526 \mathrm{E}-\mathrm{C} 2$

$0.8006 \mathrm{E}-02$

$0.1372 E-01$

$0.1454 \mathrm{E}-02$

$-0.6858 E-22$

$-0.2494 E-02$

$0.5702 E-02$

$0.5983 \mathrm{E}-02$

$-0.9390 E-03$

$-0.1289 E-01$

$-0.2253 E-01$

$-0.2648 E-01$

- $0.04632-0$

$-0.9474 E-02$

$0.5597 \mathrm{E}-03$

$0.1027 \mathrm{E}-0$

$0.1853 \mathrm{E}-01$

$0.2456 E-01$

$0.2910 E-21$

$0.2797 E-01$

$0.2516 \mathrm{E}-01$

$0.2119 \mathrm{E}-01$

$0.1658 \mathrm{E}-01$

$0.1281 \mathrm{E}-01$
A.:P

c. 3177 E-02 $0.4367 E-02$ $0.4359 E-02$ $0.6500 E-02$ $0.4762 \mathrm{E}-02$ $0.7937 E-02$ $0.3199 E-02$

$0.9818 E-C 2$

$0.1407 E-C 2$

$0.1417 E-C 1$

$0.1098 E-01$

$0.7699 E-C 2$

$0.4613 E-02$

C.5981E-52

$0.1045 E-01$

C.1494E-O1

$0.1937 E-01$

$0.2353 E-21$

$0.2685 E-01$

$0.2907 E-01$

$0.3034 \mathrm{E}-01$

0.30 e $8 E-01$

$0.3094 E-01$

$0.3075 \mathrm{E}-01$

$0.3047 E-01$

$0.3016 E-01$

$0.2977 E-01$

$0.2919 E-01$

$0.2834 E-01$

$0.2716 \mathrm{E}-01$

$0.2567 E-01$

$0.2393 E-01$

$0.2205 E-C I$

$0.2013 E-01$
$E(A) P)$

$0.488 E-02$ $0.485 E-02$ $0.4 B 7 E-02$ $0.480 \mathrm{E}-\mathrm{C2}$ $3.488 E-C 2$ $C .475 E-02$ $0.489 E-C 2$ C.473E-02 $0.452 \mathrm{E}-\mathrm{C} 2$ $0.457 \mathrm{E}-\mathrm{C} 2$ $0.462 \mathrm{E}-02$ $0.480 E-02$ $0.484=-02$ $0.500 E-C 2$ $0.479 \mathrm{E}-02$ $0.455 E-C 2$ $0.425 E-02$ $0.391 E-02$ $0.347 \mathrm{E}-\mathrm{C2}$ $0.315 \mathrm{E}-02$ $0.289 E-C 2$ $0.272 \mathrm{E}-02$ $0.272 \mathrm{E}-\mathrm{S2}$ $0.285 E-02$ $0.298 \mathrm{E}-02$ $0.307 E-02$ $0,320 E-02$ $0.339 \mathrm{E}-02$ $0.361 \mathrm{E}-02$ $0,380 \mathrm{E}-02$ $0.396 \mathrm{E}-02$ $0.409 E-02$ $0.424 E-C 2$ $0.439 \mathrm{E}-02$

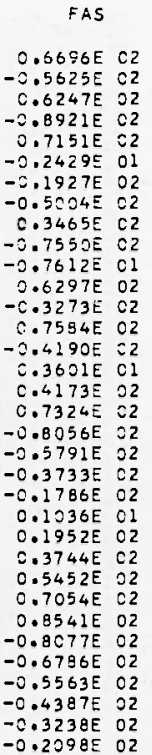

E(FAS)

$0.279 E$ OD
$0.279 E$ (2) 0.277 E 00 iD 0.277 DO II $0.277 E$ 0O 12 $-280 E$
00 $0.263 E$ OO 15 $0.262 E$ CO 16 0.274 E $00 \quad 17$ $\begin{array}{lll}0.275 E & 00 & 19 \\ 0.2825 & 00 & 19\end{array}$ $0.274 E$ OO 20 $0.274 E$ 20 21 $0.263 E 00 \quad 22$ $0.245 E$
$0.22 C E$ $00 \quad 24$ $\begin{array}{lll}0.22 C E & 00 & 24 \\ 0.1995 & 00 & 25\end{array}$ $0.179 E$ OO 26 $0.16 B E$ OO 27 . $166 \mathrm{E} 00 \quad 28$ $\begin{array}{ll}0.165 E & 00 \\ 0.165 E & 29\end{array}$

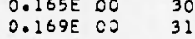
$0.179 E$ CO 32 $2.188 E$ OO 33 $0.203 E$ DO 35 $0.213 E$ OC 36 $0.224 E$ OO 37 $0.234 E$ OO 38 $\begin{array}{ll}0.242 E & 00 \\ 0.248 E & 39\end{array}$

KITAS

Ci

$-c .1571 E-i 2$

$-0.3133 E-i 2$

$0.73945-03$

$0.9497 \mathrm{E}-\mathrm{C3}$

$-0.2261 E-c 2$

$-0.4240=-02$

$0.7556=-02$

$0.1015 \mathrm{E}-01$

$-c .1465 E-C 2$

$-0.1552 E-c$.

$-0.168 \mathrm{eE}-\mathrm{O}$

$-0.7067 E-22$

$0.76035-62$

$0.2113 E-3$ :

$0.2662 \mathrm{E}-\mathrm{Cl}$

$0.2097 \mathrm{E}-\mathrm{C}$

$0.7026 \mathrm{E}-\mathrm{C} 2$

$-0.9391 E-02$

$-0.2298 \mathrm{E}-01$

$-0.3066 E-01$

$-0.3162 \mathrm{E}-01$

$-0.2662 \mathrm{E}-02$

$-0.1727 \mathrm{E}-01$

$-0.5447 \mathrm{E}-02$

$0.7132 \mathrm{E}-02$

$0.1903 \mathrm{E}-01$

$0.2921 E=01$

$0.3698 E=01$

$0.4199 \mathrm{E}=01$

$0.4413 E=01$

$0.4350 E-C 1$

$0.4030 E-01$

$0.3487 E=01$

$0.27365-01$
52

$-0.53755-32$

C. $1592 \mathrm{c}-\mathrm{C}$

$-0.5214 \mathrm{E}-02$

C. $5172 \mathrm{E}-02$

$0.5317 E-03$

$-0.48005-3$

$-0.6452 E-3$

$.612 \div=-32$

0.1460 드-

$0.3855-92$

-0.e:l gF-52

- . $1904 E-51$

$-5,2: 13 E-2$

$-1255 E-31$
$\therefore . ? 823 E-32$

$0.29925-02$

$0.2446 \mathrm{E}-01$

$0.2864 E-01$

$0.20605-01$

$0.75725-02$

$-0.6891 \mathrm{E}-32$

$-C .19 B 8 E-J 1$

$-0.2951 E-31$

$=0.3486 \mathrm{E}-0$.

$-0.3579 \mathrm{E}-01$

$-0.3269 \mathrm{E}-\mathrm{J}$

$-0.2625 E-01$

$-0.1734 E-01$

$-0.6831 E-02$

$0.4475 E-02$

$0.1585 E-01$

$0.2671 E-01$

$0.3657 E-01$

$3.4507 E-01$
ANP

$0.5092 E-32$ C. $3559 E-C 2$

$0.5266 E-02$

$0.5258 E-02$

$0.2910 E-02$

$0.6405 E-02$

$0.9561 \mathrm{E}-\mathrm{C2}$

$0.12 P 5 E-C ?$

$0.14775-0$

C.1719E-21

$0.1373 E-61$

$0.2031 \mathrm{E}-\mathrm{O}$

$0.2246 \mathrm{E}-\mathrm{O} 1$

$0.26795-C 1$

0.26 ? $7 E-01$

C. $2825 E-01$

$0.2931 E-C l$

$\mathrm{C} .3014 \mathrm{~F}-\mathrm{Cl}$

0.3 C.86-01

$0.3158 \mathrm{BE}-0$

$0.3236 \mathrm{E}-01$

C. $3322 \mathrm{E}-01$

$0.3420 E-01$

$0.3529 E-0$

$0.3649 E-01$

$0.3782 E-C l$

$0.3928 E-01$

$0.4085 E-01$

$0.4254 E-G$

$0.4436 E-01$

$0.4630 E-01$

$0.4835 E-01$

$0.5053 E-01$

$0.5283 E-01$

\section{E(A.MD)}

$0.625 E-c 2$ C. $610 \mathrm{E}-02$

$0.612 \mathrm{E}-02$

$0.594 \mathrm{~F}-02$

$0.671 \mathrm{~F}-02$

$0.639 \mathrm{E}-02$

c.589E-02

C.5E日E-02

$0.594 \mathrm{E}-02$

$0.56 . \mathrm{E}-\mathrm{C} 2$

$0.538 E-C 2$

$0.502 E-02$

$0.472 E-02$

$0.415 E-22$

$0.375 E-02$

$0.328 \mathrm{E}-\mathrm{C} 2$

$0.291 \mathrm{E}-02$

$0.254 \mathrm{E}-02$

$0.241 \mathrm{E}-\mathrm{C2}$

$0.231 \mathrm{E}-02$

$0.204 E-C 2$

$0.203 E-02$

$0.226 \mathrm{E}-02$

$0.226 \mathrm{E}-02$

$0.206 \mathrm{E}-02$

C. $207 \mathrm{E}-02$

$0.245 E=02$

$0.283 \mathrm{E}-02$

$0.294 E-C 2$

$0.279 \mathrm{E}-02$

$0.264 E-02$

$0.283 \mathrm{E}-02$

$0.337 \varepsilon-02$

$0.399 E-02$

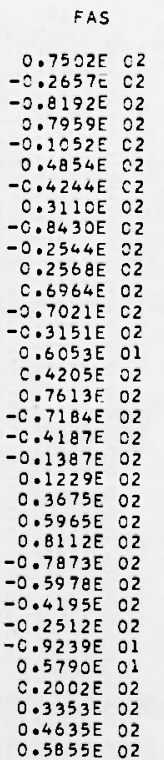

E(FAS)

$2.343 E 00$ $0.353 E 00$ 
continualion Table $\mathrm{IV}$

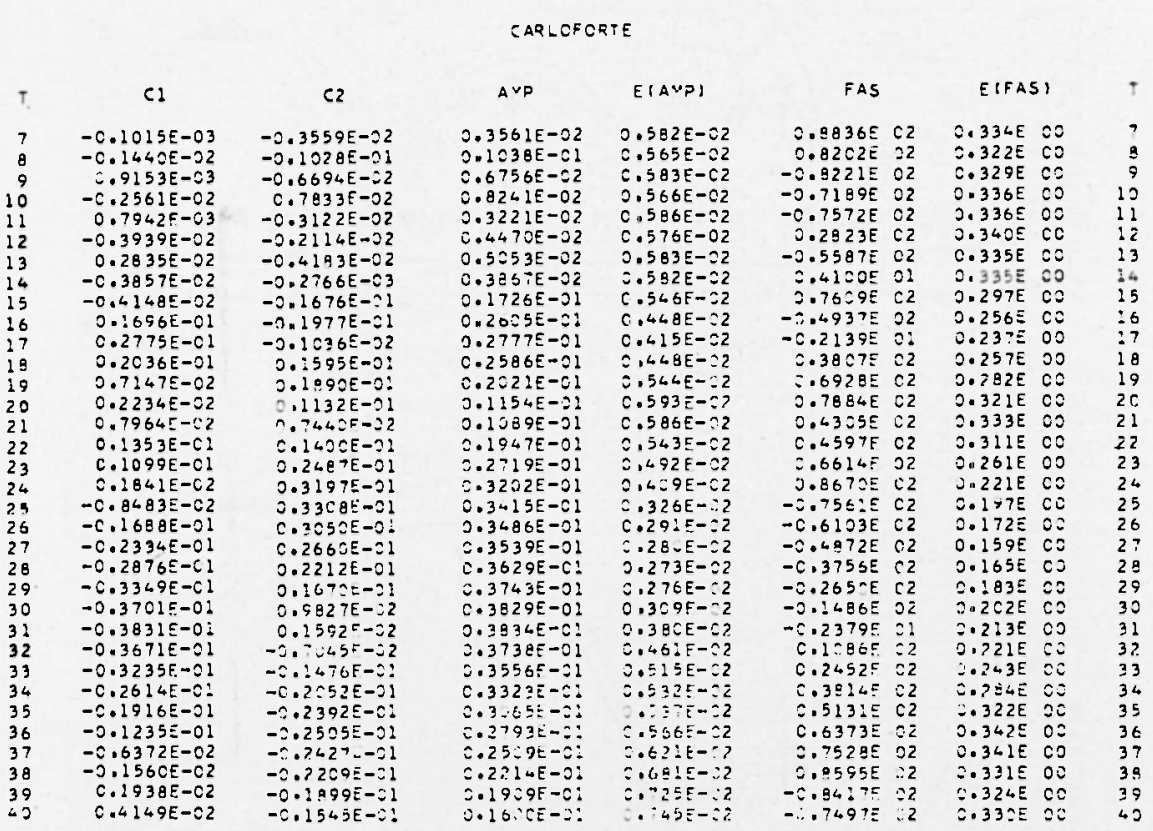

the diagrams in figs. 1 and 2 together with the respective errors $E(A)$. The values thus calculated are, however, still affected by a systematic variation depending on the $\mathbf{F 6 0}$ filter used on the observed latitude data. Actually, because of the application of the F60 filter on initial data (the latitudes given in Table II), every sinusoidal component contained in them will have its amplitude multiplied by the factor

$$
\varrho=\frac{1}{60} \frac{\sin \frac{60 \pi}{10 T}}{\sin \frac{\pi}{10 T}}
$$

The amplitudes found through the procedure described must therefore be "normalized" by dividing them by the factor $g$, which belongs to the period of each of them. The "normalized" values of the amplitudes are given in the same figs. 1 and 2.

Given the type of filter used, which presents a zero for periods of 6 years, it is opportune to consider that around this period the ampli- 


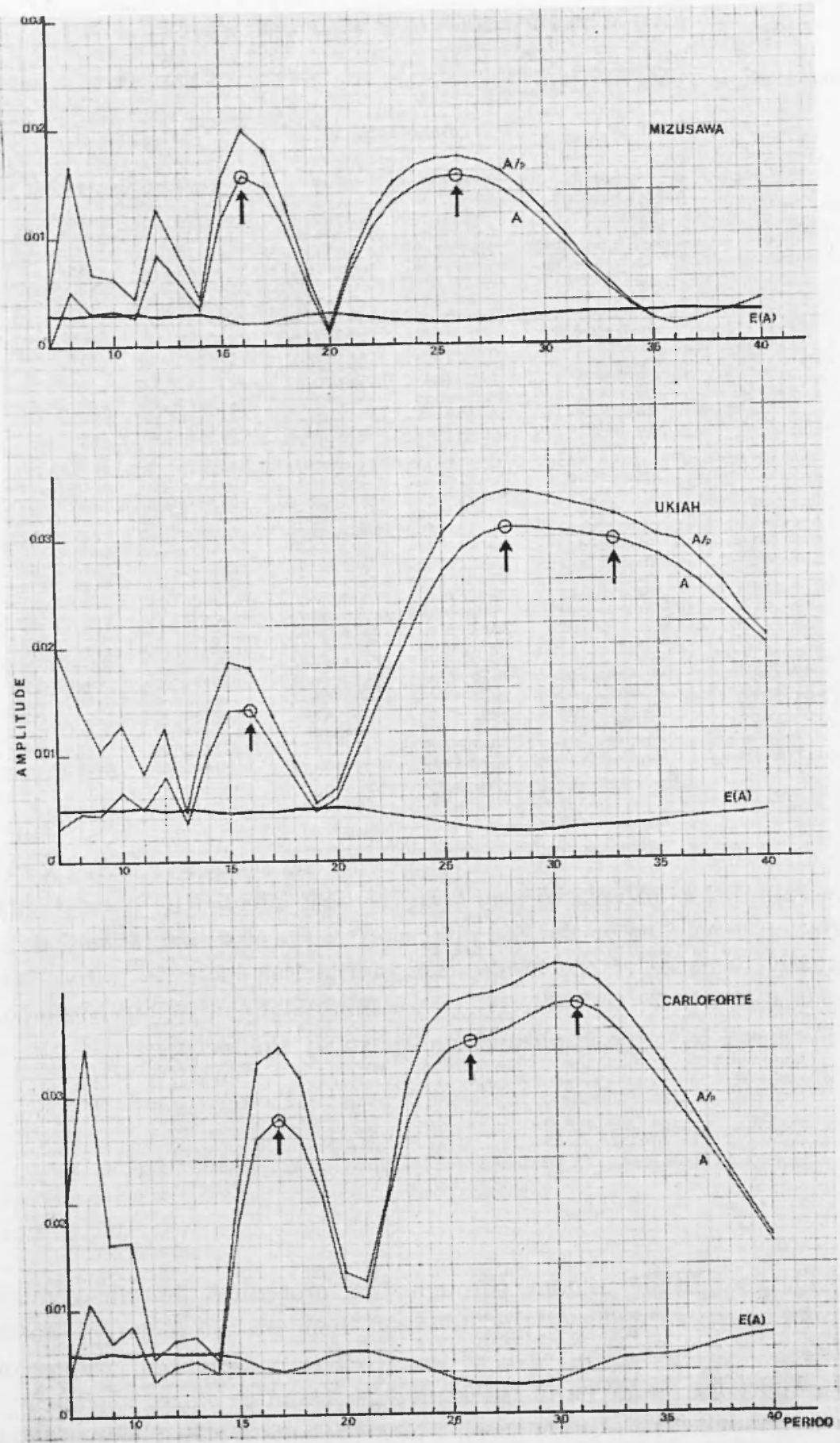

Fig. 1 - Spectrum in amplitude against period $P$ for various values of $P$. 


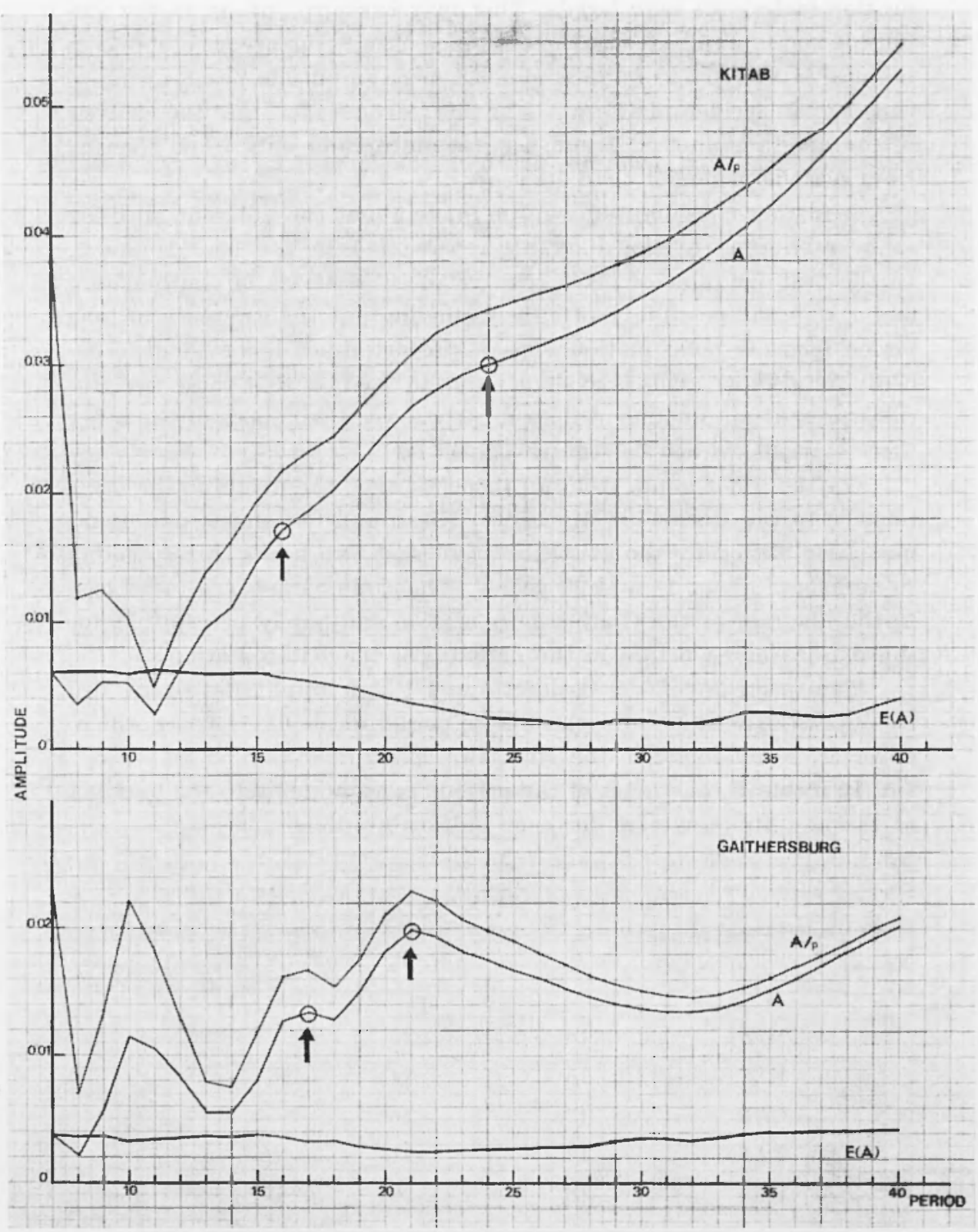

Fig. 2 - Spectrum in amplitude against period $P$ for various values of $P$. 
ficatiou factors are very large. That may cause to appear, in the amplitude spectrum diagrams, the existence of only apparent components because of the effect of the amplification of amplitude peaks owing to rauses of an accidental nature. For this reason we feel that the analysis of the diagrams in figs. 1 and 2 is certainly valid only when starting from periods of longer than 10 years.

A further consideration can be made about the different meaning to be attributed to the diagrams represented in the figs. 1 and 2 . In the two diagrams of fig. 2 relative to the stations of Gaithersburg and Ukiah the possibility of clearly singling out the existence of long period terms in polar motion appears, in fact, much less evident, especially for Ukiah. This is evidently due to the fact that these two stations present an amount of data greatly lower than those of the other three stations, as can be seen in Table III.

On the other hand, from an inspection, of the diagrams in fig. 1 relative to the stations of Mizusawa, Kitab and Carloforte, one is immediately struck by the existence of at least two peaks corresponding to periods of about 16 and 26 years. The same periods are to be seen in the diagram of the Gaithersburg station and barely perceptible, for the reasons given before in the diagram of the Kitab station.

The spectrum of the Carloforte and Ukiah amplitudes seems also to hint at the existence of a third large period of about 31 year's which, however, is not found in the Mizusawa spectrum.

In Table $\mathrm{V}$ the values of the periods corresponding to the maxima of the amplitude spectra for each station are given.

Table V

\begin{tabular}{|l|l|l|l|}
\hline & $T_{1}$ & $T_{2}$ & $T_{3}$ \\
\hline MIZ & 16 & 26 & - \\
KIT & 16 & 24 & - \\
CAR & 17 & 26 & 31 \\
GAI & 17 & 21 & - \\
UKI & 16 & 28 & 33 \\
\hline
\end{tabular}

If, as it is logical, more weight is attributed to the spectra relative to the stations of fig. 1 , it can be concluded, overlooking the period 
indicated as $T_{3}$ in Table $V$, that polar motion seems to be affected by periodical variations around 16 and 26 years. These two periorls seem to be confirmed by the trend of the errors $E(A)$ of the amplitudes represented in figs. 1 and 2 and of the errors in the phases given in Table IV. In correspondence to them, in fact, both the calculated amplitude and phase errors present minimum values.

The order of approximation with which these periods are observed can thus be directly deduced from the diagrams in fig. 1.

In Table VI the values calculated by means of [2] and observed by the measurement of band width of the quantity $1 / Q$ expressed in years are given for the stations of Mizusawa, Carloforte and Ukiall.

Table VI

\begin{tabular}{|c|c|c|c|c|}
\hline & $\left(1 / Q_{26}\right)_{\mathrm{cal}}$ & $\left(1 / Q_{16}\right)_{\mathrm{cal}}$ & $\left(1 / Q_{26}\right)_{\mathrm{obs}}$ & $\left(1 / Q_{\mathrm{6}}\right)_{\mathrm{obs}}$ \\
\cline { 2 - 2 } & 3.7 & 2.3 & 4.8 & 1.9 \\
$\mathrm{CAR}$ & 3.7 & 2.3 & 4.0 & 2.2 \\
$\mathrm{UKI}$ & 3.7 & 2.3 & 6.0 & 2.0 \\
\hline
\end{tabular}

The data in this Table point up the good agreement between the observed and calculated values of $1 / Q$ and an uncertainty calculated in the observed values of $T_{1}$ and $T_{2}$ of \pm 2 and \pm 5 years respectively.

In Table VII we find instead the phases expressed in degrees corresponding to the periods $T_{1}, T_{2}$ and $T_{3}$ for each of the five stations of the IISS.

Table VII

\begin{tabular}{|l|c|c|c|}
\hline & $F_{1}$ & $F_{2}$ & $F_{3}$ \\
\hline MIZ & -48 & +56 & - \\
KIT & +155 & +108 & - \\
CAR & -21 & -119 & +156 \\
GAI & -20 & +108 & - \\
UKI & +104 & -18 & +71 \\
\hline
\end{tabular}




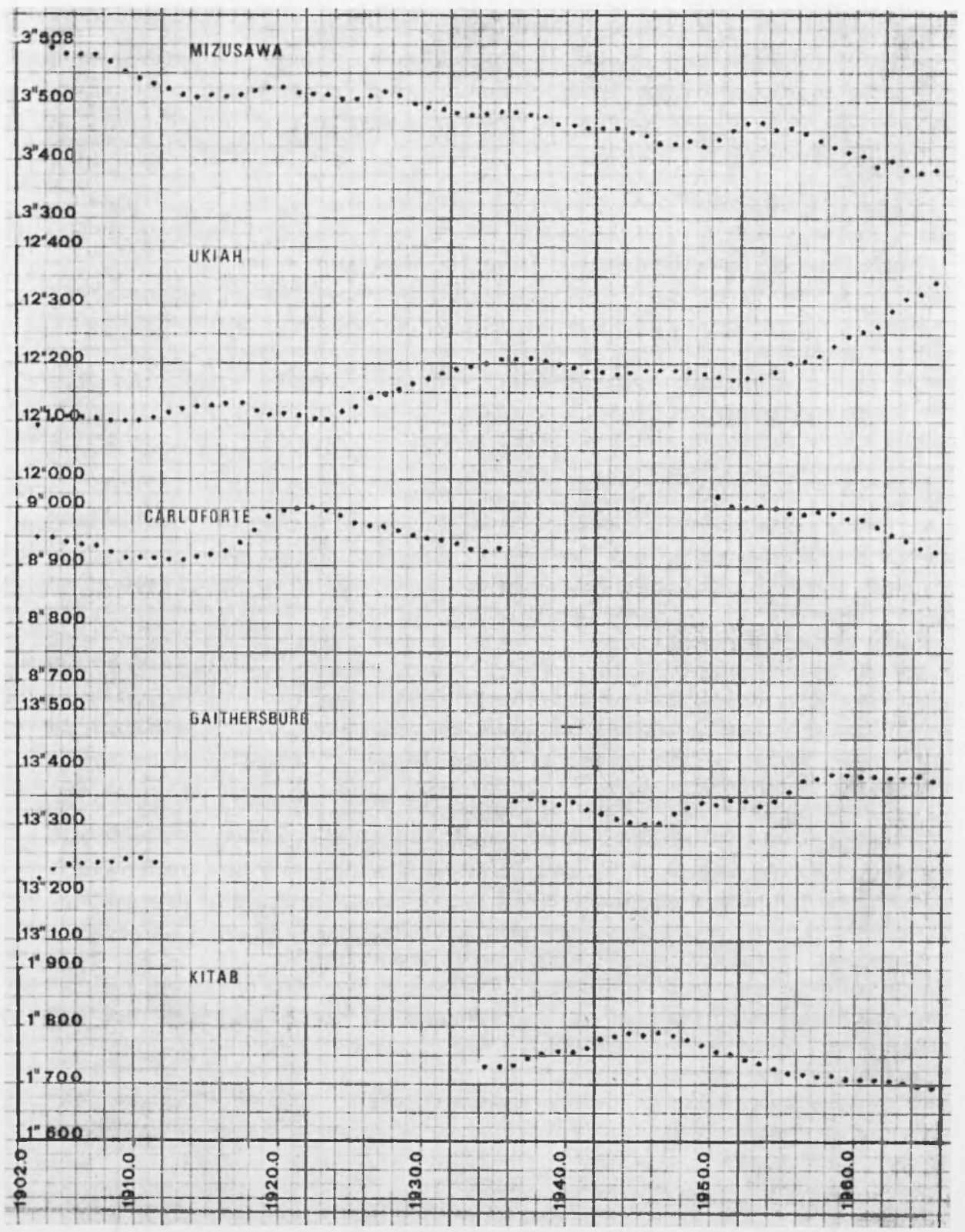

Fig. 3 - Long period and secular variations observed in latitudes for the period 1903.5-1965.5 for the I.L.S. Stations. 


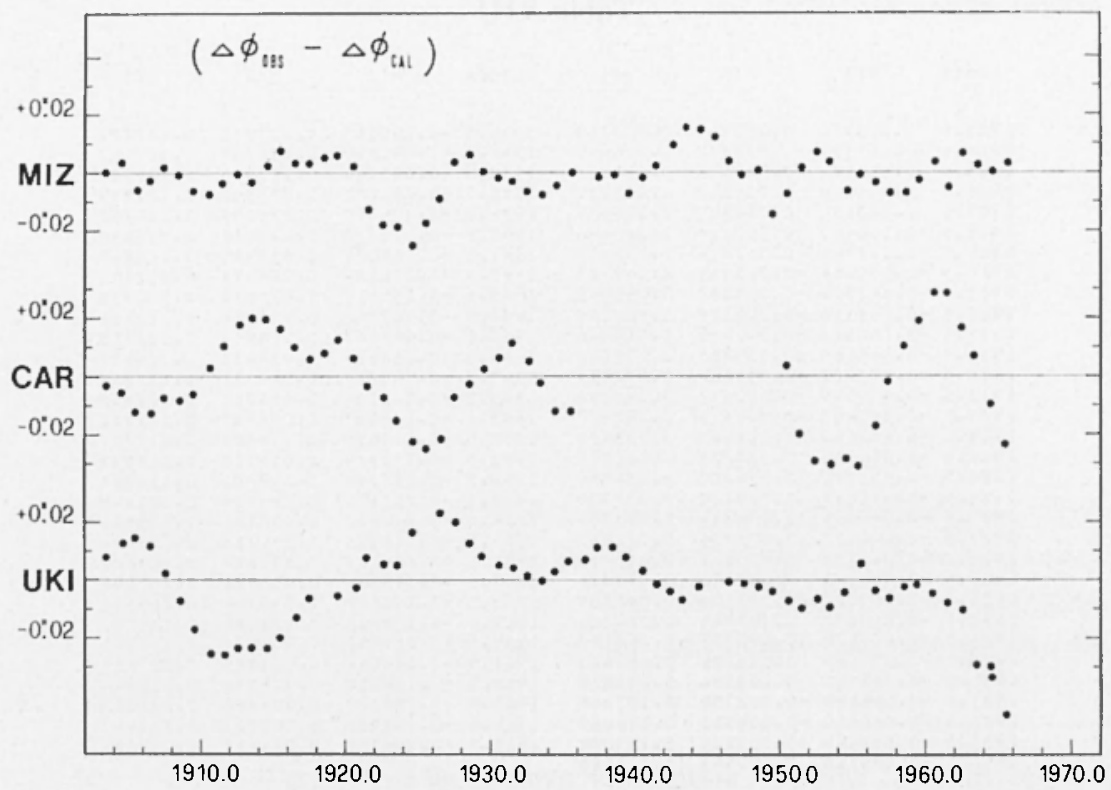

Fig. 4 - Residuals between observed and calculated values of the latitude variations $\Delta \Phi$ for the stations of Mizusawa, Carloforte and I Tials.

2.4 - In fig. 4 are represented the residuals $(0-C)$ of the differences of the quantities $\Delta \Phi$ observed (which trend is given in fig. 3 ) and calculated by means of the relation

$$
\Delta \Phi^{(i)}=a^{(i)}+b^{(i)} t+A_{1}{ }^{(i)} \sin \left(\frac{9 \pi t}{\pi_{1}}+F_{1}^{(i)}\right)+A_{2}{ }^{(i)} \sin \left(\frac{2 \pi t}{T_{2}}+F_{2}{ }^{(i)}\right)[4]
$$

in which the values of the amplitudes $A$ and the phases $F$ are taken from Table IV in correspondence to the periods $T_{1}=16$ years, $T_{0}=26$ years. The values of the latitudes $A \Phi(i)$ calculated by means of the relation [4] are given, at less of one constant, in Table VIII.

The amplitude and the distributions of these residuals seems put in evidence the existence of mean period components in the polar motion of the order of 10 years. For the stations of Carloforte and Ukiah there is also evidence for very long fluctuation closed to periorl of about 30 years pointed out by the diagrams of the fig. 1 . 
Talle VIII

\begin{tabular}{|c|c|c|c|c|c|c|c|}
\hline EPOCA & $\mathrm{x}: 2$ & CAñ & UKI & EPOCA & $M 12$ & CAR & UKI \\
\hline $\begin{array}{l}1903.5 \\
1904.5 \\
1905.5 \\
1906.5 \\
1907.5 \\
1908.5 \\
1909.5 \\
1910.5 \\
1911.5 \\
1912.5 \\
1913.5 \\
1914.5 \\
1915.5 \\
1916.5 \\
1917.5 \\
1918.5 \\
1919.5 \\
1920.5 \\
1921.5 \\
1922.5 \\
1923.5 \\
1924.5 \\
1925.5 \\
1926.5 \\
1927.5 \\
1928.5 \\
1929.5 \\
1930.5 \\
1931.5 \\
1932.5 \\
1933.5 \\
1934.5\end{array}$ & $\begin{array}{r}0.012311 \\
0.013937 \\
0.013144 \\
0.009474 \\
0.002836 \\
-0.066461 \\
-0.017746 \\
-0.036064 \\
-0.042301 \\
-0.053936 \\
-0.062192 \\
-0.068165 \\
-0.079921 \\
-0.075539 \\
-0.067487 \\
-0.062560 \\
-0.056756 \\
-0.051140 \\
-0.046690 \\
-0.044169 \\
-0.044027 \\
-0.046351 \\
-0.050873 \\
-0.057032 \\
-0.064072 \\
-0.071174 \\
-0.077589 \\
-0.062756 \\
-0.086388 \\
-0.088510 \\
-0.089449 \\
-0.019765\end{array}$ & $\begin{array}{r}0.022347 \\
0.023372 \\
0.022614 \\
0.012109 \\
0.012439 \\
0.005228 \\
-0.011616 \\
-0.023329 \\
-0.033387 \\
-0.046175 \\
-0.042425 \\
-0.039365 \\
-0.032564 \\
-0.017491 \\
-0.032412 \\
0.013647 \\
0.037721 \\
0.054800 \\
0.068109 \\
0.076334 \\
0.073791 \\
0.07551 \\
0.067176 \\
0.055103 \\
0.040955 \\
0.026555 \\
0.013624 \\
0.003554 \\
-0.302759 \\
-0.005015 \\
-0.003501 \\
0.000993\end{array}$ & $\begin{array}{l}0.002268 \\
0.006491 \\
0.011328 \\
0.017132 \\
0.024077 \\
0.032194 \\
0.046853 \\
0.049783 \\
0.058142 \\
0.065116 \\
0.569946 \\
0.072046 \\
0.071112 \\
0.067192 \\
0.060757 \\
0.052425 \\
0.043379 \\
0.034752 \\
0.027728 \\
0.023356 \\
0.022382 \\
0.025216 \\
0.031824 \\
0.041759 \\
0.05422 C \\
0.068157 \\
0.082403 \\
0.095828 \\
0.107468 \\
0.116640 \\
0.123006 \\
0.126585\end{array}$ & $\begin{array}{l}1935.5 \\
1936.5 \\
1937.5 \\
1938.5 \\
1939.5 \\
1940.5 \\
1941.5 \\
1942.5 \\
1943.5 \\
1944.5 \\
1945.5 \\
1946.5 \\
1947.5 \\
1948.5 \\
1949.5 \\
1950.5 \\
1951.5 \\
1952.5 \\
1953.5 \\
1954.5 \\
1955.5 \\
1956.5 \\
1957.5 \\
1958.5 \\
1959.5 \\
1960.5 \\
1961.5 \\
1962.5 \\
1963.5 \\
1964.5 \\
1965.5\end{array}$ & $\begin{array}{l}-c .090153 \\
-0.091316 \\
-0.093840 \\
-0.090082 \\
-0.104099 \\
-0.111620 \\
-0.120075 \\
-0.128674 \\
-0.136521 \\
-0.142749 \\
-0.146657 \\
-0.147834 \\
-0.146222 \\
-0.142154 \\
-0.136313 \\
-0.125655 \\
-0.123279 \\
-0.118284 \\
-0.115611 \\
-0.115920 \\
-0.119495 \\
-0.126211 \\
-0.135541 \\
-0.146646 \\
-0.158483 \\
-0.169953 \\
-0.180054 \\
-0.188010 \\
-0.193373 \\
-0.196067 \\
-0.196385\end{array}$ & $\begin{array}{l}0.067335 \\
0.014258 \\
0.020578 \\
0.025381 \\
0.028188 \\
0.028998 \\
0.028285 \\
0.026893 \\
0.025874 \\
0.026289 \\
0.028997 \\
0.034483 \\
0.042735 \\
0.053210 \\
0.064880 \\
0.076366 \\
0.086128 \\
0.092701 \\
0.094918 \\
0.092112 \\
0.084238 \\
0.071919 \\
0.056391 \\
0.039359 \\
0.002786 \\
0.008634 \\
-0.001388 \\
-0.006058 \\
-0.004798 \\
0.002257 \\
0.014278\end{array}$ & $\begin{array}{l}0.127722 \\
0.127607 \\
0.125166 \\
0.122939 \\
0.126966 \\
0.119698 \\
0.119343 \\
0.119361 \\
0.120998 \\
0.122361 \\
0.123515 \\
0.124089 \\
0.123868 \\
0.122458 \\
0.121311 \\
0.119707 \\
0.118693 \\
0.118983 \\
0.121245 \\
0.123980 \\
0.133424 \\
0.143480 \\
0.155699 \\
0.165310 \\
0.183297 \\
0.196521 \\
0.207658 \\
0.216344 \\
0.221306 \\
0.222447 \\
0.219895\end{array}$ \\
\hline
\end{tabular}

\section{3. - LONG TERM PER'TURBATIONS IN POLAR MO'TION}

3.1 - Because of the existence of the long period terms shown up by the analysis of the series of latiturles observed in the IIS stations, polar motion presents long term fluctuations. These fluctuations may be expressed as a function of the periods $T_{1}=16$ and $T_{2}=26$ years, knowing the amplitudes and the phases of the two components $x$ and $y$ of polar motion by means of the relations

$$
\begin{aligned}
& x=A_{x} \sin \left(\frac{9 \pi t}{T}+B_{x}\right), \\
& y=A_{y} \cos \left(\frac{2 \pi t}{T}+B_{y}\right) .
\end{aligned}
$$

Substituting these latter in the well-known relation of Kostinsky

$$
\Delta \Phi(i)=A(i) \sin \left(\frac{9 \pi t}{\pi}+\bar{F}^{\prime(i)}\right)=x \cos \lambda(i)+y \sin \lambda^{(i)}
$$

it is possible to calculate the quantities $A_{x}, A_{y}, B_{x}$ and $B_{y}$ con- 
tained in [6]. By doing the calculations, the following expressions are arrived at:

$$
\begin{aligned}
& x_{26}=0^{\prime \prime} .030 \sin \left(\frac{2 \pi t}{26}+123\right) \\
& y_{26}=0^{\prime \prime} .026 \cos \left(\frac{2 \pi t}{26}+197\right) \\
& x_{16}=0^{\prime \prime} .021 \sin \left(\frac{2 \pi t}{16}-49\right) \\
& y_{16}=0^{\prime \prime} .008 \cos \left(\frac{2 \pi t}{16}+78\right)
\end{aligned}
$$

These represent the long term components of polar motion. The comparison of these relations with those previously calculated (11) and given by [1] better shows up the fact that the explicitation of the term with period $T_{1}$ leads to a variation in the amplitude and the phases in the other term.

4.2 - The existence of long term variations in polar motion revealed, as has been said, by Markowitz $\left(^{8}\right)$ has led various theoreticians to attempt a plausible explanation of this phenomenon.

This is not the best place to enter into details on these theories. We feel, however, that it is useful to point out that Abraham ('), and later Busse ( $\left.{ }^{2}\right)$ proposed two theories based on a "beat" phenomenon. In particular, the theory proposed by Busse provides for a long term polar motion ( 24 years) caused by precessional motion in the inner core on an eigen-frequency. This motion is supposedly characterized by the existence of a long term libration of positive circular polarization. The polar motion expressed by equations [6] may be held to be in agreement with what is expected according to this theory.

\section{REFERENCES}

(1) Aвrahay II. J., 1968. - Fluctuations in the motion of the mean Pole and the rotation of the Earth, "Continental drift, secular motion of the Pole, and rotation of the Earth", I.A.U. Symp. No. 32, D. Reidel Publ. Comp. Dordrecht-Holland.

(2) Busse F. H., 1970. - The dynamical coupling between inner core and mantle of the Earth and the 24-year libration of the pole, "Displacement Fields and the Rotation of the Farth", D. Reidel Publ. Comp. DordrechtHolland. 
(3) Castaxgia G., 1971. - Componenti a lungo termine del moto polare, "Tesi di laurea in Matematica ", Univ. Studi di Cagliari.

(4) Colombo G., Sinapiro I. I., 1968. - Theoretical Model for the Chandler Wobble, "Nature", 156, 217.

(5) Gaposcinin E. M., 1971. - Analysis of pole position from 1S46 to 1970, "Rotation of the Earth", I.A.U. Symp. No. 48, Morioka (Japan) (in press).

$\left({ }^{6}\right)$ II ATtori T., 1959. - On the secular motion of the pole, "Publ. Inter. Isatit. Obs. Mizusawa", VIII (1), 1.

(7) IIJna S., 197I. - On the Chandler and Annual Ellipses in the polar motion, "Rotation of the Earth", I.A.U. Symp. No. 48, Morioka (Japan), (in press).

(8) МАRКоWITz W., 1960. - Latitude and Longitude and the secular motion of the pole, "Methods and Techniques in Geophysies", Interseience Publ. Ltd., Isondon.

( ${ }^{9}$ MElchior P., 1949. - Sur la variation de la période chandlérienne du mouvement du pôle et la rigidité de la Terre, "Comm. Obs. R. Belgique", No. 10.

(10) MELChIOR P., 1952. - Sur une nouvelle méthode d'analyse du mouvement du pôle à la surjace de la Terre, "Comm. Obs. R. Belgique", No. 36.

(11) Proverbio E., Carta F., Mazzoleni F., 1971. - Secular and long-term variation of polar molion, "Rotation of the Earth", I.A.U. Symp. No. 48, Morioka (Japan), (in press).

(12) Proverbio E., Carta F., Mazzoleni F., 1970. - Filtered latitude system for analysis of the polar motion, "Circ. Staz. Astron. Inter. Latit.", Carloforte-Cagliari, No. 1.

(13) Proverbio E., Carta, F., Mazzoleni, F., 1969. - Sistemi di latitudine omogenee e variazioni delle coordinate del polo, "Contr. Oss. Astr." Milano-Merate, No. 319. 